\title{
Astrocytes and microglia in acute cerebral injury underlying cerebral palsy associated with preterm birth
}

\author{
Carina Mallard', Joanne O. Davidson², Sidhartha Tan ${ }^{3}$, Colin R. Green ${ }^{4}$, Laura Bennet ${ }^{2}$, Nicola J. Robertson ${ }^{5}$ \\ and Alistair Jan Gunn²
}

Cerebral palsy is one of the most devastating consequences of brain injury around the time of birth, and nearly a third of cases are now associated with premature birth. Compared with term babies, preterm babies have an increased incidence of complications that may increase the risk of disability, such as intraventricular hemorrhage, periventricular leukomalacia, sepsis, and necrotizing enterocolitis. The response to injury is highly dependent on brain maturity, and although cellular vulnerability is well documented, there is now evidence that premyelinating axons are also particularly sensitive to ischemic injury. In this review, we will explore recent evidence highlighting a central role for glia in mediating increased risk of disability in premature infants, including excessive activation of microglia and opening of astrocytic gap junction hemichannels in spreading injury after brain ischemia, in part likely involving release of adenosine triphosphate (ATP) and overactivation of purinergic receptors, particularly in white matter. We propose the hypothesis that inflammation-induced opening of connexin hemichannels is a key regulating event that initiates a vicious circle of excessive ATP release, which in turn propagates activation of purinergic receptors on microglia and astrocytes. This suggests that developing effective neuroprotective strategies for preterm infants requires a detailed understanding of glial responses.

Cerebral palsy (CP) is one of the most devastating consequences of perinatal brain damage and affects $\sim 2$ of 1,000 live births. Over one-third of all cases are associated with premature birth (1) and a further 15\% with acute encephalopathy in term infants (2). Cerebral palsy has one of the very highest indexes of burden of disease, which is from the loss of potential productive members of society and from direct burdens on the individual, family, and social institutions that last the entire life (3).

The seminal concept established by recent research is that the injury leading to cerebral palsy is not static, making treatment possible. In term animals, acute, reversible hypoxia-ischemia is associated with a "latent" phase of recovery often lasting $6-8 \mathrm{~h}$, followed by "secondary" mitochondrial failure associated with seizures and cell swelling and, ultimately, cell death (4). Although considerable cell death occurs in the secondary phase, this injury can then trigger a chronic or tertiary phase of further progressive cell death, repair, and remodeling (5). Confirming that many cells are still viable in the first hours after injury, prolonged, moderate hypothermia started in the latent phase, well after reperfusion, can dramatically reduce ischemic brain damage in near-term fetal sheep (4). Through the efforts of many researchers and large multicenter controlled trials, it is now well established in term infants that mild to moderate hypothermia induced in the first $6 \mathrm{~h}$ after birth with neonatal encephalopathy, and continued for at least $72 \mathrm{~h}$, can significantly improve survival without disability (6). This striking result confirms the relevance of decades of preclinical research.

The challenge is now that hypothermia alone is only partially protective; many infants still die or survive with disability (6). Furthermore, hypothermia may not be applicable to preventing cerebral palsy in premature infants. There is a strong historical link between mild hypothermia and increased mortality in preterm newborns (7), and recently, a phase I trial of cooling for preterm infants was stopped by the US Food and Drug Administration because of potential concerns about intracerebral hemorrhage. Furthermore, unlike term infants, the etiology of injury in preterm children appears to be multifactorial, and it is often unclear precisely when brain injury occurred, partly because neurological signs are much subtler than at term and partly because the underlying insults are more diffuse (8). Given that hypothermia is only effective in a narrow window after injury (4), the hypoxic-ischemic event would have to be close to birth for treatment to be effective. Thus, to establish protective protocols for the preterm infant, there is a need for better understanding of underlying mechanisms of damage in this population. Our goal in this review is to highlight evidence for novel mechanisms of brain injury that may contribute to disability in premature infants.

\section{ACUTE PERINATAL HYPOXIA-ISCHEMIA AND INFECTION/ INFLAMMATION IN PRETERM INFANTS}

Modern neuroimaging studies of surviving preterm infants show a consistent pattern of early white matter injury followed by abnormal development of gray matter structures 


\section{Mechanisms of perinatal brain injury $\quad$ Review}

(9). The precise causes of the long-term maldevelopment are still surprisingly controversial, but now there is increasing evidence for a complex mixture of acute neuronal and axonal damage affecting the cerebral white matter, cerebral cortex, basal ganglia, brain stem, and cerebellum, along with secondary abnormalities of maturation $(8,10)$. In preclinical studies, the response to injury is highly dependent on brain maturity. The susceptibility of the periventricular white matter does not appear to be related to greater ischemia in that region, at least in the sheep (11). Rather, it is closely correlated with the relative vulnerability of late oligodendrocyte progenitors in rabbit, sheep, and human $(11,12)$. Furthermore, in vitro, central premyelinating axons are reported to be much more vulnerable to ischemic injury than adjacent myelinated axons or smaller axons that had not reached the stage of radial expansion (13), likely contributing to the high risk of axonopathy in necrotic periventricular white matter lesions (14).

Early imaging, postmortem, and electroencephalogram (EEG) recordings suggest that the acute neural injury occurs broadly around the perinatal period in approximately twothirds of cases, and many cases occur well before the onset of labor, whereas injury after the early neonatal period represents only $10 \%$ of cases $(15,16)$. Both overt asphyxia, including need for resuscitation at birth, and frank/clinical infection at the time of birth ostensibly account for some cases $(17,18)$. Recent studies, however, have highlighted a role for both earlier and subtler insults in the majority of cases. For example, the Extremely Low Gestational Age Newborns (ELGAN) Study reported that severe intrauterine growth restriction and evidence of placental vascular thrombosis were associated with impaired neurodevelopmental outcome at $2 \mathrm{y}$ of age (19), consistent with a role for long-standing, prenatal hypoxia. After birth, although low blood pressure is common, the evidence for an association between hypotension and adverse outcomes is limited, as reviewed earlier (20). However, blood pressure is only a surrogate marker of changes in cerebral circulation; robust measurements of cerebral blood flow in gray and white matter that could specifically link cerebral ischemia with longterm outcome are now essential.

Similarly, subclinical infection is more common than frank sepsis and also highly associated with adverse outcomes $(18,21)$. For example, increased cord blood tumor necrosis factor (TNF)- $\alpha$ levels have been associated with depression of the EEG in the first few days of life, white matter injury on cranial ultrasound, and risk of handicap at $2 \mathrm{y}$ of age (22). In the ELGAN study, necrotizing enterocolitis or bacteremia, combined with ventilation on d 14, was strongly associated with impaired development (23). Strikingly, the combination of intrauterine growth retardation with increased inflammatory markers in the first $2 \mathrm{wk}$ of life was associated with greater increase in risk of severe neurodevelopmental impairment compared with either of these alone (24). These findings raise the possibility that both chronic low-grade injury/substrate limitation and infection/inflammation, either independently or together, may impair brain development.

\section{CLINICAL EVIDENCE FOR MICROGLIAL ACTIVATION IN PRETERM BRAIN INJURY}

Microglia, which represent 5-15\% of brain cells, constitute the pool of immune-competent resident cerebral macrophages (25). The normal preterm brain shows transient clusters of amoeboid microglia in the periventricular crossroads of growing axonal pathways in the white matter (26). The periventricular fiber crossroads are rich in axonal guidance and extracellular matrix molecules, and it is believed that microglia in these regions may help regulate the development of axonal bundles and elimination of excessive transcallosal projections during brain development (27). The crossroads appear to be particularly vulnerable to injury in the very preterm brain, and in postmortem material are highly associated with both focal and diffuse white matter injury $(10,28)$. Given that microglia release proinflammatory cytokines, particularly TNF- $\alpha$ and, to a lesser extent, interleukin- $1 \beta$, at the early stages of white matter damage in newborns, these human postmortem studies implicate inflammation as important contributors to white matter injury (29).

\section{STAGES OF MICROGLIA ACTIVATION IN THE IMMATURE BRAIN}

The timing of initiation of microglia activation is often unknown, and diverse experimental insults activate microglia. In preterm fetal sheep, hypoxia-ischemia (11), systemic asphyxia (30), and exposure to endotoxins are associated with significant activation of microglia and induction of proinflammatory cytokines and other inflammatory mediators $(31,32)$. Direct fetal infection is not required to trigger inflammation and neural injury. In fetal sheep, uteroplacental inflammation induced by endotoxins is associated with significant microglial activation and macrophage infiltration in the fetal brain (33). Similarly, in rabbits, after maternal endotoxin exposure in late gestation, motor deficit in the rabbit pups was associated with microglia activation detected by positron emission tomography imaging (34), although the observed motor deficits were mild to moderate. Thus, neuroinflammation appears to be a critical series of events involved in white matter damage regardless of the initial trigger of injury.

Experimental studies using neonatal rodents have examined the time course of microglia responses induced by excitotoxicity or hypoxia-ischemia. Increased expression of markers for microglia and macrophages is seen around lesions within the first $24 \mathrm{~h}$ after the initial insult. Microglia accumulation peaks at $\sim 2-4$ d, but it may persist for days to weeks in some brain regions (35). At least in the acute phase after neonatal stroke in rats, the inflammatory cells in the brain appear to consist of resident microglia $\left(\mathrm{CD} 45 \mathrm{low} /\right.$ medium/CD11b $\mathrm{b}^{+}$, rather than invading monocytes $\left(\mathrm{CD} 45 \mathrm{high} / \mathrm{CD} 11 \mathrm{~b}^{+}\right)(36)$. This is followed by several waves of inflammation from $24 \mathrm{~h}$ to $7 \mathrm{mo}$ after injury, with early expression of $\mathrm{CD}_{1} \mathrm{bb}^{+}$and $\mathrm{CD} 11 \mathrm{c}^{+}$antigenpresenting cells and naïve $\mathrm{CD}_{4} \mathrm{rb}^{+} \mathrm{T}$ lymphocytes. In contrast, 3 mo after hypoxia-ischemia, pronounced activation of CD45rb ${ }^{-} \mathrm{T}$ lymphocytes expressing CD69 and CD25 was seen in the damaged hemisphere (37). Similarly, in preterm fetal 
sheep, umbilical cord occlusion is associated with widespread activation and proliferation of microglia, along with a significant influx of neutrophils into the brain $7 \mathrm{~d}$ after asphyxia (38). Taken together, these data suggest that acute injury leads to sustained inflammation in the preterm brain, which may in turn increase the risk of future cognitive dysfunction or increase vulnerability to further injury (39).

Nevertheless, it is important to appreciate that chronic inflammation may not be "all bad." Microglia can adopt complex phenotypes, allowing them to participate in cytotoxic responses, immune regulation, and injury resolution at different times (40). Thus, although activated microglia can contribute to brain injury through the production of excitatory amino acids, proteases, nitric oxide, reactive oxygen species, and other proinflammatory mediators (41), they can also have important restorative functions after injury. Exogenous microglia can be neuroprotective (42), and depletion of microglia worsens injury in both adult (43) and neonatal (44) rodents. These data support the importance of time and place for understanding the role of inflammatory processes and are consistent with the variable impact of anti-inflammatory drugs on neuroprotection, discussed in the following section.

\section{ANTI-INFLAMMATORY TREATMENT FOR NEUROPROTECTION}

Many drugs have been proposed to attenuate brain damage by inhibiting inflammation. The broad-spectrum antibiotic minocycline, a derivative of tetracycline, reduced focal brain infarction and had strong anti-inflammatory effects in adult rodents (45), and nearly completely prevented brain damage after hypoxia-ischemia in neonatal rats (46). Furthermore, in endotoxin-induced models of brain damage, minocycline given repeatedly, both before and after lipopolysaccharide injection, was associated with decreased number of activated microglial cells, decreased elevation of interleukin- $1 \beta$ and TNF- $\alpha$, and reduced number of inducible nitric oxide synthase (iNOS)expressing cells (47). However, although minocycline ameliorated hypoxic-ischemic brain injury in neonatal rat pups, treatment increased injury in mouse pups (48). Furthermore, minocycline only transiently reduced the volume of injury at $24 \mathrm{~h}$ but not $7 \mathrm{~d}$ after middle cerebral artery occlusion in 7-d-old rat pups; importantly, the transient amelioration of damage was largely independent of microglial activation (49).

Nuclear factor- $\kappa \mathrm{B}$ (NF- $\mathrm{kB})$, an important modulator of inflammation that also controls transcription of genes promoting apoptosis and other cellular injury response genes, is induced biphasically after hypoxia-ischemia in neonatal rats, being maximal at 3-6 and $24 \mathrm{~h}$ (50). Ethyl pyruvate, a stable and lipophilic derivative of pyruvate, has been proposed to ameliorate ischemic injury in neonatal rodents by inhibition of NF-kB (51). Subsequent studies, however, found no effect of ethyl pyruvate (52), and there are no studies in species other than rats, which limits the interpretation of the results. Decoy oligonucleotides (IgG-kB) that penetrate into the brain and bind and inhibit NF- $\mathrm{kB}$ reduce transcription of the messenger RNA for proinflammatory cytokines (53) and reduced brain injury when given before neonatal hypoxia-ischemia (54). Others have shown that selective NF- $\mathrm{KB}$ inhibition has neuroprotective effects that are predominantly mediated via antiapoptotic mechanisms, including prevention of accumulation of p53, independent of cytokine production (55). The timing of NF- $\mathrm{kB}$ inhibition was critical, as neuroprotection was only observed when early activation was blocked, whereas prevention of both early and late NF- $\mathrm{KB}$ activity aggravated damage (50). Overall, the studies suggest that totally blocking inflammation is not a reliable strategy for neuroprotection.

\section{MECHANISMS OF SPREAD OF INFLAMMATION-INDUCED INJURY THROUGH HEMICHANNELS AND PURINERGIC RECEPTORS IN GLIAL CELLS}

One of the most striking aspects of hypoxia-ischemia is the progressive evolution of damage into previously uninjured areas over days to weeks after the insult (56). The mechanisms of this spread are not understood, but gap junctions between glia have been suggested to play an important role through a "gap junction-mediated bystander effect" (57). Gap junctions are intercellular channels that link the cytoplasms of adjacent cells, permitting the exchange of small molecules and ions. Under normal physiological conditions, gap junctions function in an open state, but undocked hemichannels have either been reported to remain closed or contribute to purinergic signaling (58). Nonspecific, global gap junction blockers, such as carbenoxolone, glycyrrhizic acid, heptanol, and octanol, are reported to provide neuroprotection in vitro (59), after stroke in adult rats (60) and in rat pups after intrauterine hypoxiaischemia (61).

More recent evidence now implicates connexin hemichannels in the propagation of injury. Hemichannels, or connexons, are half of a gap junction channel that sits in the unopposed membrane of a cell, before the formation of new channels. Opening of connexin hemichannels has been shown to occur as a result of ischemia, deprivation of oxygen and glucose, metabolic inhibition, or low extracellular calcium ion $\left(\mathrm{Ca}^{2+}\right)$ levels (62-64). This may cause disruption of the resting membrane potential, release of cytotoxic levels of adenosine triphosphate (ATP) (58) and glutamate (65), and uptake of water resulting in cell swelling and rupture (66).

The timing of hemichannel opening remains unclear because much of the literature does not clearly distinguish between that occurring during, as opposed to that occurring after, ischemia. A study by Thompson et al. (67) showed that hemichannels can open within $9.7 \mathrm{~min}$ after the onset of oxygen and glucose deprivation in acutely isolated hippocampal neurons. In contrast, astrocyte cultures exposed to 3 or $6 \mathrm{~h}$ of hypoxia in artificial cerebrospinal fluid showed increased dye uptake following $1 \mathrm{~h}$ of reoxygenation, which was abolished by pharmacological treatments known to inhibit connexin 43 (Cx43), but not pannexin hemichannels, suggesting that hemichannel opening occurs in consequential amounts after the end of hypoxia-ischemia (64). In contrast, metabolic inhibition of cultured astrocytes with antimycin A and iodoacetic acid resulted in increased dye uptake from $40 \mathrm{~min}$ after the 


\section{Mechanisms of perinatal brain injury $\quad$ Review}

onset of inhibition, suggesting hemichannel opening during metabolic inhibition (63). Conversely, $48 \mathrm{~h}$ of hypoxia reduced ATP release in endothelial cell cultures, suggesting hemichannel closure during hypoxia (68). In addition, hypoxia resulted in $\mathrm{Cx} 43$-serine368 phosphorylation, which causes hemichannels to switch from an open to a closed state (68). Cell typespecific changes may be critical. Protein expression of Cx32, predominantly expressed in oligodendroglia, is normally highest at $60 \%$ gestation in fetal sheep, whereas $\mathrm{Cx} 43$ increases with age (69). Studies in Cx43 knockout mice show greater injury after ischemia than in control animals (70), likely indicating the adverse effects of loss of gap junctions as opposed to that of hemichannels.

We have previously reported that prolonged blockade of $\mathrm{Cx} 43$ hemichannels with a specific mimetic peptide $(50 \mu \mathrm{mol} / \mathrm{kg} / \mathrm{h}$ for $1 \mathrm{~h}$, followed by $50 \mu \mathrm{mol} / \mathrm{kg} / 24 \mathrm{~h}$ ) significantly improved neurological outcomes in near-term fetal sheep when applied from $90 \mathrm{~min}$ after $30 \mathrm{~min}$ of cerebral ischemia (71). This included a dramatic reduction in seizures and the incidence of status epilepticus, improved recovery of EEG power, and sleep state cycling, and improved survival of oligodendrocytes, with intermediate neuronal survival between sham controls and vehicle-treated animals. The improved recovery of EEG activity with postischemic hemichannel blockade may be related to better cortical cell survival as suggested by the strong correlation between EEG power and cortical neuronal number (71). Improved cell survival was likely related to a combination of acutely reduced injury spread and subsequently reduced astrogliosis and chronic inflammation, as shown recently after spinal injury in adult rats (72). Although oligodendrocyte numbers were improved in the near-term fetal sheep, it is unclear whether blockade of $\mathrm{Cx} 43$ hemichannels would also be effective in the more preterm fetal sheep, at an age where premyelinating white matter is enriched in oligodendrocyte progenitors (11), similar to the preterm human infant.

Postischemic opening of hemichannels can lead to greater releases of ATP $(58,73)$. Activation of P2Y receptors by ATP can transiently increase intracellular calcium, which consequently further enhances opening of hemichannels, resulting in "ATP-induced ATP release" (73-75). This release of ATP potentiates the spread of calcium waves through the astrocytic syncytium, and in spinal cord injuries, ATP release in peritraumatic areas has been found to be associated with excessive neuronal firing (76). Of particular relevance to preterm brain

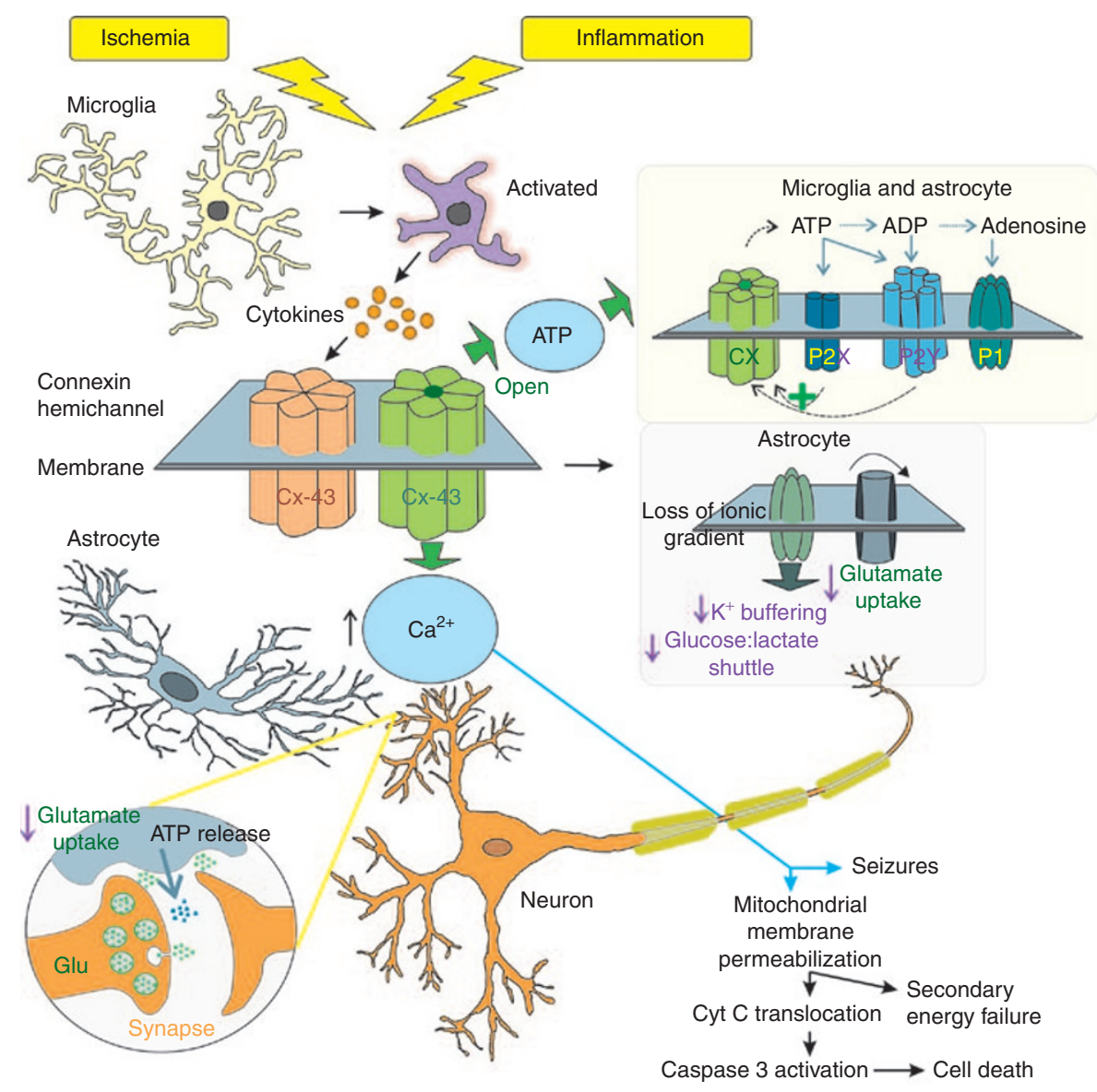

Figure 1. Flow diagram outlining the hypothesized relationship between microglia activation and astrocytic connexin 43 (Cx43) hemichannel opening and preterm brain injury. We propose that inflammation-induced opening of connexin hemichannels is a key regulating event that initiates a vicious circle of excessive adenosine triphosphate (ATP) release. This, in turn, propagates activation of purinergic receptors on microglia and astrocytes. Thus, in the early phase after injury, the release of ATP links astrocyte impairment to persistent activation of microglia, which can result in injury to neurons, axons (shown), and oligodendrocytes (not shown for brevity). ADP, adenosine diphosphate; Cyt C, cytochrome C. 
injury, in vitro, $\mathrm{P} 2 \mathrm{X} 7$ receptor antagonists, enzymatic ATP degradation, and hemichannel blockade all reduced oligodendrocyte mitochondrial depolarization and oxidative stress, reduced ischemic damage to optic nerves (77), and improved functional recovery after ischemia (77). These data are highly consistent with the finding of reduced seizure activity after hemichannel blockade (71).

\section{ACTIVATED MICROGLIA STIMULATE HEMICHANNEL OPENING IN ASTROCYTES}

Recent quantitative human data demonstrate that white matter injury in preterm infants is consistently associated with a diffuse glial reaction involving both astrocytes and microglia (10). Consistent with this finding, there is increasing preclinical evidence from older ages that the microglial and astrocytic responses to inflammation are closely linked. Both release of cytokines, such as interleukin-1 $\beta$ and TNF- $\alpha$ by activated microglia in vitro, and Staphylococcus aureus brain infection in mice, are associated with reduced gap junctional communication but paradoxically increased $\mathrm{Cx} 43$ hemichannel activity (78). Intriguingly, hemichannel activity was increased by cytokine exposure in vitro, through a p38 mitogen-activated protein kinase-dependent pathway, even though $\mathrm{Cx} 43$ levels were reduced in vitro (79), whereas bacterial infection was associated with induction of Cx43 (78). Enhanced hemichannel opening resolved by $7 \mathrm{~d}$ after bacterial infection (78), highlighting the importance of timing of exposure. We propose that inflammation-induced opening of connexin hemichannels is a key regulating event that initiates a vicious circle of excessive ATP release. This in turn, promotes activation of purinergic receptors on microglia and astrocytes. Thus, in the early phase after injury, release of ATP links astrocyte impairment to persistent activation of microglia, which can result in injury to neurons, axons (Figure 1), and oligodendrocytes. Beyond these early effects, astrocytes are recognized to play multiple roles in the pathogenesis of chronic brain injury, including release of a broad array of neurotrophic factors and factors inhibitory to axonal regeneration and oligodendrocyte maturation (80). Thus, it is not unreasonable to speculate that connexin hemichannels may also play a role in the evolution of the chronic phase of gray or white matter injury.

\section{CONCLUSION}

Astrocytes and microglia, key supporting cells in the brain, are now accepted as important players in the great disaster of perinatal brain injury. However, it is easily forgotten that they may have multiple, time-dependent effects, such that under some circumstances, they promote injury whereas at other times or under different conditions, they may protect neurons and oligodendrocytes and support neurorestoration. The studies reviewed here suggest that astroglia are likely to be important mediators of early injury after hypoxia-ischemia and infection, through overexpression of connexin hemichannels, leading to ATP release and activation of purinergic receptors and propagation of proinflammatory microglia that add to injury in the early postinjury phase. However, in the medium to longer term after brain insult, microglia may contribute to resolution of injury and repair by adopting restorative functions.

There are many remaining gaps in our knowledge, particularly with reference to the "time and place" of these responses. What determines the microglial switch from damage to repair after injury? When do astrocytes mediate injury and when do they transition to supporting cell survival after injury? What is the role of the interactions between astrocytes and microglia? When and how does astrogliosis inhibit rather than support neurorestoration? Better understanding of these relationships is essential to design appropriate interventions to help protect the injured preterm brain.

\section{STATEMENT OF FINANCIAL SUPPORT}

The authors' work reported in this review has been supported by the Health Research Council of New Zealand, Lottery Health Board of New Zealand, the Auckland Medical Research Foundation, the March of Dimes Birth Defects Foundation, the US National Institutes of Health (Bethesda, MD) grant R21 NS063141-01A1, Swedish Medical Research Council (VR 2012-2992), Swedish government grant in Public Health Service at the Sahlgrenska University Hospital (grant ALFGBG-142881), European Union grant FP7 (Neurobid, HEALTH-F2-2009-241778), the Leducq Foundation (France; grant DSRR P34404), and the Åhlén Stiftelsen Foundation (Sweden).

Disclosure: The authors declare no conflicts of interest.

\section{REFERENCES}

1. Committee on Understanding Premature Birth and Assuring Healthy Outcomes. Preterm Birth: Causes, Consequences, and Prevention. In: Behrman RE, Butler AS, eds. Washington, DC: Institute of Medicine of the National Academies, 2007. (http://books.nap.edu/openbook.php?record_ id=11622\&page $=1.1$ March 2013.)

2. McIntyre S, Badawi N, Brown C, Blair E. Population case-control study of cerebral palsy: neonatal predictors for low-risk term singletons. Pediatrics 2011;127:e667-73.

3. Centers for Disease Control and Prevention. Economic costs associated with mental retardation, cerebral palsy, hearing loss, and vision impairment-United States, 2003. MMWR Morb Mortal Wkly Rep 2004;53:57-9.

4. Gunn AJ, Gunn TR. The 'pharmacology' of neuronal rescue with cerebral hypothermia. Early Hum Dev 1998;53:19-35.

5. Stone BS, Zhang J, Mack DW, Mori S, Martin LJ, Northington FJ. Delayed neural network degeneration after neonatal hypoxia-ischemia. Ann Neurol 2008;64:535-46.

6. Edwards AD, Brocklehurst P, Gunn AJ, et al. Neurological outcomes at 18 months of age after moderate hypothermia for perinatal hypoxic ischaemic encephalopathy: synthesis and meta-analysis of trial data. BMJ 2010;340:c363.

7. Gunn AJ, Bennet L. Brain cooling for preterm infants. Clin Perinatol 2008;35:735-48, vi-vii.

8. Volpe JJ. Brain injury in premature infants: a complex amalgam of destructive and developmental disturbances. Lancet Neurol 2009;8:110-24.

9. Inder TE, Huppi PS, Warfield S, et al. Periventricular white matter injury in the premature infant is followed by reduced cerebral cortical gray matter volume at term. Ann Neurol 1999;46:755-60.

10. Buser JR, Maire J, Riddle A, et al. Arrested preoligodendrocyte maturation contributes to myelination failure in premature infants. Ann Neurol 2012;71:93-109.

11. Back SA, Riddle A, Dean J, Hohimer AR. The instrumented fetal sheep as a model of cerebral white matter injury in the premature infant. Neurotherapeutics 2012;9:359-70.

12. Buser JR, Segovia KN, Dean JM, et al. Timing of appearance of late oligodendrocyte progenitors coincides with enhanced susceptibility of preterm rabbit cerebral white matter to hypoxia-ischemia. J Cereb Blood Flow Metab 2010;30:1053-65.

13. Alix JJ, Zammit C, Riddle A, et al. Central axons preparing to myelinate are highly sensitivity to ischemic injury. Ann Neurol 2012;72:936-51. 


\section{Mechanisms of perinatal brain injury $\quad$ Review}

14. Riddle A, Maire J, Gong X, et al. Differential susceptibility to axonopathy in necrotic and non-necrotic perinatal white matter injury. Stroke 2012;43:178-84.

15. Becher JC, Bell JE, Keeling JW, McIntosh N, Wyatt B. The Scottish perinatal neuropathology study: clinicopathological correlation in early neonatal deaths. Arch Dis Child Fetal Neonatal Ed 2004;89:F399-407.

16. Kubota T, Okumura A, Hayakawa F, et al. Combination of neonatal electroencephalography and ultrasonography: sensitive means of early diagnosis of periventricular leukomalacia. Brain Dev 2002;24:698-702.

17. Low JA, Killen H, Derrick EJ. Antepartum fetal asphyxia in the preterm pregnancy. Am J Obstet Gynecol 2003;188:461-5.

18. Wu YW, Colford JM Jr. Chorioamnionitis as a risk factor for cerebral palsy: a meta-analysis. JAMA 2000;284:1417-24.

19. Helderman JB, O'Shea TM, Kuban KC, et al.; ELGAN study Investigators. Antenatal antecedents of cognitive impairment at 24 months in extremely low gestational age newborns. Pediatrics 2012;129:494-502.

20. Bennet L, Booth LC, Drury PP, Quaedackers JS, Gunn AJ. Preterm neonatal cardiovascular instability: does understanding the fetus help evaluate the newborn? Clin Exp Pharmacol Physiol 2012;39:965-72.

21. Grether JK, Nelson KB. Maternal infection and cerebral palsy in infants of normal birth weight. JAMA 1997;278:207-11.

22. Wikström S, Ley D, Hansen-Pupp I, Rosén I, Hellström-Westas L. Early amplitude-integrated EEG correlates with cord TNF-alpha and brain injury in very preterm infants. Acta Paediatr 2008;97:915-9.

23. O'Shea TM, Shah B, Allred EN, et al.; ELGAN Study Investigators. Inflammation-initiating illnesses, inflammation-related proteins, and cognitive impairment in extremely preterm infants. Brain Behav Immun 2013;29:104-12.

24. Leviton A, Fichorova RN, O'Shea TM, et al.; ELGAN Study Investigators. Two-hit model of brain damage in the very preterm newborn: small for gestational age and postnatal systemic inflammation. Pediatr Res 2013;73:362-70.

25. Perry VH, Hume DA, Gordon S. Immunohistochemical localization of macrophages and microglia in the adult and developing mouse brain. Neuroscience 1985;15:313-26.

26. Vasung L, Huang H, Jovanov-Miloševic N, Pletikos M, Mori S, Kostovic I. Development of axonal pathways in the human fetal fronto-limbic brain: histochemical characterization and diffusion tensor imaging. J Anat 2010;217:400-17.

27. Rochefort N, Quenech'du N, Watroba L, Mallat M, Giaume C, Milleret C. Microglia and astrocytes may participate in the shaping of visual callosal projections during postnatal development. J Physiol Paris 2002;96:183-92.

28. Verney C, Pogledic I, Biran V, Adle-Biassette H, Fallet-Bianco C, Gressens P. Microglial reaction in axonal crossroads is a hallmark of noncystic periventricular white matter injury in very preterm infants. J Neuropathol Exp Neurol 2012;71:251-64.

29. Kadhim H, Tabarki B, Verellen G, De Prez C, Rona AM, Sébire G. Inflammatory cytokines in the pathogenesis of periventricular leukomalacia. Neurology 2001;56:1278-84.

30. Bennet L, Roelfsema V, George S, Dean JM, Emerald BS, Gunn AJ. The effect of cerebral hypothermia on white and grey matter injury induced by severe hypoxia in preterm fetal sheep. J Physiol (Lond) 2007;578(Pt 2):491-506.

31. Dean JM, van de Looij Y, Sizonenko SV, et al. Delayed cortical impairment following lipopolysaccharide exposure in preterm fetal sheep. Ann Neurol 2011;70:846-56.

32. Mathai S, Booth LC, Davidson JO, et al. Acute on chronic exposure to endotoxin in preterm fetal sheep. Am J Physiol Regul Integr Comp Physiol 2013;304:R189-97.

33. Hutton LC, Castillo-Melendez M, Smythe GA, Walker DW. Microglial activation, macrophage infiltration, and evidence of cell death in the fetal brain after uteroplacental administration of lipopolysaccharide in sheep in late gestation. Am J Obstet Gynecol 2008;198:117.e1-11.

34. Kannan S, Saadani-Makki F, Balakrishnan B, et al. Magnitude of [(11)C] PK11195 binding is related to severity of motor deficits in a rabbit model of cerebral palsy induced by intrauterine endotoxin exposure. Dev Neurosci 2011;33:231-40.
35. McRae A, Gilland E, Bona E, Hagberg H. Microglia activation after neonatal hypoxic-ischemia. Brain Res Dev Brain Res 1995;84:245-52.

36. Denker SP, Ji S, Dingman A, et al. Macrophages are comprised of resident brain microglia not infiltrating peripheral monocytes acutely after neonatal stroke. J Neurochem 2007;100:893-904.

37. Winerdal M, Winerdal ME, Kinn J, Urmaliya V, Winqvist O, Adén U. Long lasting local and systemic inflammation after cerebral hypoxic ischemia in newborn mice. PLoS ONE 2012;7:e36422.

38. Jellema RK, Lima Passos V, Zwanenburg A, et al. Cerebral inflammation and mobilization of the peripheral immune system following global hypoxia-ischemia in preterm sheep. J Neuroinflammation 2013;10:13.

39. Fleiss B, Gressens P. Tertiary mechanisms of brain damage: a new hope for treatment of cerebral palsy? Lancet Neurol 2012;11:556-66.

40. Mosser DM, Edwards JP. Exploring the full spectrum of macrophage activation. Nat Rev Immunol 2008;8:958-69.

41. Svedin P, Hagberg H, Sävman K, Zhu C, Mallard C. Matrix metalloproteinase-9 gene knock-out protects the immature brain after cerebral hypoxiaischemia. J Neurosci 2007;27:1511-8.

42. Imai F, Suzuki H, Oda J, et al. Neuroprotective effect of exogenous microglia in global brain ischemia. J Cereb Blood Flow Metab 2007;27:488-500.

43. Lalancette-Hébert M, Gowing G, Simard A, Weng YC, Kriz J. Selective ablation of proliferating microglial cells exacerbates ischemic injury in the brain. J Neurosci 2007;27:2596-605.

44. Faustino JV, Wang X, Johnson CE, et al. Microglial cells contribute to endogenous brain defenses after acute neonatal focal stroke. J Neurosci 2011;31:12992-3001.

45. Yrjänheikki J, Tikka T, Keinänen R, Goldsteins G, Chan PH, Koistinaho J. A tetracycline derivative, minocycline, reduces inflammation and protects against focal cerebral ischemia with a wide therapeutic window. Proc Natl Acad Sci USA 1999;96:13496-500.

46. Arvin KL, Han BH, Du Y, Lin SZ, Paul SM, Holtzman DM. Minocycline markedly protects the neonatal brain against hypoxic-ischemic injury. Ann Neurol 2002;52:54-61.

47. Fan LW, Pang Y, Lin S, Rhodes PG, Cai Z. Minocycline attenuates lipopolysaccharide-induced white matter injury in the neonatal rat brain. Neuroscience 2005;133:159-68.

48. Tsuji M, Wilson MA, Lange MS, Johnston MV. Minocycline worsens hypoxic-ischemic brain injury in a neonatal mouse model. Exp Neurol 2004;189:58-65.

49. Fox C, Dingman A, Derugin N, et al. Minocycline confers early but transient protection in the immature brain following focal cerebral ischemiareperfusion. J Cereb Blood Flow Metab 2005;25:1138-49.

50. Nijboer CH, Heijnen CJ, Groenendaal F, May MJ, van Bel F, Kavelaars A. A dual role of the NF-kappaB pathway in neonatal hypoxic-ischemic brain damage. Stroke 2008;39:2578-86.

51. Shen $\mathrm{H}, \mathrm{Hu} \mathrm{X}$, Liu C, et al. Ethyl pyruvate protects against hypoxic-ischemic brain injury via anti-cell death and anti-inflammatory mechanisms. Neurobiol Dis 2010;37:711-22.

52. Gressens P, Le Verche V, Fraser M, et al. Pitfalls in the quest of neuroprotectants for the perinatal brain. Dev Neurosci 2011;33:189-98.

53. Qiu J, Hu X, Nesic O, et al. Effects of NF-kappaB oligonucleotide "decoys" on gene expression in P7 rat hippocampus after hypoxia/ischemia. J Neurosci Res 2004;77:108-18.

54. Fabian RH, Perez-Polo JR, Kent TA. A decoy oligonucleotide inhibiting nuclear factor-kappaB binding to the IgGkappaB consensus site reduces cerebral injury and apoptosis in neonatal hypoxic-ischemic encephalopathy. J Neurosci Res 2007;85:1420-6.

55. Nijboer CH, Heijnen CJ, Groenendaal F, May MJ, van Bel F, Kavelaars A. Strong neuroprotection by inhibition of NF-kappaB after neonatal hypoxia-ischemia involves apoptotic mechanisms but is independent of cytokines. Stroke 2008;39:2129-37.

56. Thornton JS, Ordidge RJ, Penrice J, et al. Temporal and anatomical variations of brain water apparent diffusion coefficient in perinatal cerebral hypoxic-ischemic injury: relationships to cerebral energy metabolism. Magn Reson Med 1998;39:920-7. 
57. Lin JH, Weigel H, Cotrina ML, et al. Gap-junction-mediated propagation and amplification of cell injury. Nat Neurosci 1998;1:494-500.

58. Kang J, Kang N, Lovatt D, et al. Connexin 43 hemichannels are permeable to ATP. J Neurosci 2008;28:4702-11.

59. Frantseva MV, Kokarovtseva L, Naus CG, Carlen PL, MacFabe D, Perez Velazquez JL. Specific gap junctions enhance the neuronal vulnerability to brain traumatic injury. J Neurosci 2002;22:644-53.

60. Rawanduzy A, Hansen A, Hansen TW, Nedergaard M. Effective reduction of infarct volume by gap junction blockade in a rodent model of stroke. J Neurosurg 1997;87:916-20.

61. de Pina-Benabou MH, Szostak V, Kyrozis A, et al. Blockade of gap junctions in vivo provides neuroprotection after perinatal global ischemia. Stroke 2005;36:2232-7.

62. Li H, Liu TF, Lazrak A, et al. Properties and regulation of gap junctional hemichannels in the plasma membranes of cultured cells. J Cell Biol 1996;134:1019-30.

63. Contreras JE, Sánchez HA, Eugenin EA, et al. Metabolic inhibition induces opening of unapposed connexin 43 gap junction hemichannels and reduces gap junctional communication in cortical astrocytes in culture. Proc Natl Acad Sci USA 2002;99:495-500.

64. Orellana JA, Hernández DE, Ezan P, et al. Hypoxia in high glucose followed by reoxygenation in normal glucose reduces the viability of cortical astrocytes through increased permeability of connexin 43 hemichannels. Glia 2010;58:329-43.

65. Ye ZC, Wyeth MS, Baltan-Tekkok S, Ransom BR. Functional hemichannels in astrocytes: a novel mechanism of glutamate release. J Neurosci 2003;23:3588-96.

66. Danesh-Meyer HV, Kerr NM, Zhang J, et al. Connexin 43 mimetic peptide reduces vascular leak and retinal ganglion cell death following retinal ischaemia. Brain 2012;135(Pt 2):506-20.

67. Thompson RJ, Zhou N, MacVicar BA. Ischemia opens neuronal gap junction hemichannels. Science 2006;312:924-7.

68. Faigle M, Seessle J, Zug S, El Kasmi KC, Eltzschig HK. ATP release from vascular endothelia occurs across $\mathrm{Cx} 43$ hemichannels and is attenuated during hypoxia. PLoS ONE 2008;3:e2801.
69. Sadowska GB, Stopa EG, Stonestreet BS. Ontogeny of connexin 32 and 43 expression in the cerebral cortices of ovine fetuses, newborns, and adults. Brain Res 2009;1255:51-6.

70. Nakase T, Söhl G, Theis M, Willecke K, Naus CC. Increased apoptosis and inflammation after focal brain ischemia in mice lacking connexin 43 in astrocytes. Am J Pathol 2004;164:2067-75.

71. Davidson JO, Green CR, Nicholson LF, et al. Connexin hemichannel blockade improves outcomes in a model of fetal ischemia. Ann Neurol 2012;71:121-32.

72. O'Carroll SJ, Gorrie CA, Velamoor S, Green CR, Nicholson LF. Connexin 43 mimetic peptide is neuroprotective and improves function following spinal cord injury. Neurosci Res 2013;75:256-67.

73. Stout CE, Costantin JL, Naus CC, Charles AC. Intercellular calcium signaling in astrocytes via ATP release through connexin hemichannels. J Biol Chem 2002;277:10482-8.

74. Cotrina ML, Lin JH, Alves-Rodrigues A, et al. Connexins regulate calcium signaling by controlling ATP release. Proc Natl Acad Sci USA 1998;95:15735-40.

75. Baroja-Mazo A, Barberà-Cremades M, Pelegrín P. The participation of plasma membrane hemichannels to purinergic signaling. Biochim Biophys Acta 2013;1828:79-93.

76. Peng W, Cotrina ML, Han X, et al. Systemic administration of an antagonist of the ATP-sensitive receptor P2X7 improves recovery after spinal cord injury. Proc Natl Acad Sci USA 2009;106:12489-93.

77. Domercq M, Perez-Samartin A, Aparicio D, Alberdi E, Pampliega O, Matute C. P2X7 receptors mediate ischemic damage to oligodendrocytes. Glia 2010;58:730-40.

78. Karpuk N, Burkovetskaya M, Fritz T, Angle A, Kielian T. Neuroinflammation leads to region-dependent alterations in astrocyte gap junction communication and hemichannel activity. J Neurosci 2011;31:414-25.

79. Retamal MA, Froger N, Palacios-Prado N, et al. Cx43 hemichannels and gap junction channels in astrocytes are regulated oppositely by proinflammatory cytokines released from activated microglia. J Neurosci 2007;27:13781-92.

80. Xu X, Warrington AE, Bieber AJ, Rodriguez M. Enhancing CNS repair in neurological disease: challenges arising from neurodegeneration and rewiring of the network. CNS Drugs 2011;25:555-73. 